\title{
RETENÇÃo DE ÁGUA E DESENVOLVIMENTO DO FEIJÃo CAUPI EM FUNÇÃo dO USO DE POLÍMERO HIDRORRETENTOR NO SOLO
}

\author{
Janielle Souza Pereira ${ }^{1}$, Nelci Olszevski² \& Jeisa Cruz da Silva ${ }^{3}$
}

1 - Engenheira Agrícola e Ambiental, Mestranda em Engenharia Agrícola, UNIVASF, Juazeiro/BA, janielle.engenheira@gmail.com

2 - Engenheira Agrônoma, Professora Associada III da UNIVASF, Juazeiro/BA, nelci.olszevski@univasf.edu.br

3 - Graduanda em Engenharia Agrícola e Ambiental, UNIVASF, Juazeiro/BA, jeisa_cruz@hotmail.com

\author{
Palavras-chaves: \\ características biométricas \\ hidrogel \\ qualidade do solo
}

Vigna unguiculata L

\section{RESUMO}

O feijão caupi ou feijão de corda é uma das principais culturas da atividade econômica no nordeste brasileiro e apresenta boa tolerância à seca e às altas temperaturas, tendo sua produtividade condicionada pelo estresse hídrico advindo dos longos períodos de seca na região. Assim, objetivo do trabalho foi a avaliação do potencial do polímero hidrorretentor na melhoria da retenção de água, das características biométricas e da produtividade da cultura do feijão caupi em solo de textura arenosa. O delineamento experimental foi em blocos inteiramente casualizados, com sete tratamentos e quatro repetições. Cada parcela foi composta por um vaso com capacidade de $7 \mathrm{~L}$, com solo e a devida quantidade de polímero hidrorretentor ou ausência do mesmo (testemunha). Foram semeadas quatro sementes por vaso e, após a germinação, realizou-se o desbaste, mantendo-se duas plântulas. Durante e ao final do ciclo da cultura, foram avaliados parâmetros biométricos e de produtividade, e determinadas a umidade e a curva de retenção de água no solo. A utilização do polímero hidrorretentor aumentou a retenção de água e melhorou grande parte das propriedades morfológicas e produtivas da cultura. Dentre as dosagens avaliadas, as proporções de 1,50;2,00 e 4,00 $\mathrm{g} \mathrm{L}^{-1}$ se apresentaram como as que mais favoreceram ao desenvolvimento vegetal.

\section{Keywords:}

biometrics characteristics

hydrogel

soil quality

Vigna unguiculata L

\section{WATER RETENTION AND DEVELOPMENT OF COWPEA BEAN DUE THE APPLICATION OF HYDROGEL POLYMER IN SOIL}

\section{ABSTRACT}

Cowpea bean is one of the main economic activity's crops in the Northeast of Brazil. In addition, this crop presents a good tolerance to drought and high temperatures, so that its productivity is conditioned by the water stress coming from the long periods of drought in the region. Therefore, the aim of this work was to evaluate the potential of the hydrogel polymer to improve water retention, biometric characteristics and productivity of cowpea in sandy soil. The experimental design was of randomized complete blocks with seven treatments and four replications. Each plot was composed of a vessel with capacity of $7 \mathrm{~L}$, filled with soil and a proper amount of hydrogel polymer or its absence (control). Four seeds per pot were sown and, after germination, the thinning was performed, maintaining two seedlings. Biometric and productivity parameters were evaluated during the crop cycle and at its end. In addition, the moisture and the soil water retention curve was determined. The use of the hydrogel polymer increased water retention and greatly improved the morphological and productive properties of the crop. Among the dosages evaluated, the proportions of $1.50 ; 2.00$ and $4.00 \mathrm{~g} \mathrm{~L}-1$ showed to be the most favorable dose for the plant development. 


\section{INTRODUÇÃO}

Estima-se que $30 \%$ do feijão produzido no Brasil advém do caupi (Vigna unguiculata L.), representando cerca de $3 \%$ do PIB agrícola nacional, com a região nordeste se destacando na produção (66,4\% em 2014) (BEZERRA et al., 2014; COUTINHO et al., 2014).

Entretanto, os longos períodos de seca da região influenciam negativamente a produção (COUTINHO et al., 2014; SOUSA et al., 2015; TERCEIRO et al., 2016), apesar da boa tolerância da cultura aos baixos níveis hídricos e às altas temperaturas (TAGLIAFERRE et al., 2013; TERCEIRO et al., 2016). Assim, algumas práticas conservacionistas têm sido adotadas na tentativa de conservar a umidade do solo, a exemplo da incorporação de matéria orgânica, do terraceamento, do uso mulching vertical e da aplicação de polímeros sintéticos (KLEIN \& KLEIN, 2014).

Tais polímeros, denominados hidrorretentores ou hidrogel ou polímero hidroabsorvente, quando aplicados ao solo, são altamente hidrofílicos, pois possuem grupos carboxílicos que facilitam a retenção de água com posterior disponibilização para as plantas (CARVALHO et al., 2013; CONTE et al., 2014), minimizando problemas de estiagens, principalmente em solos arenosos nas regiões áridas e semiáridas. Ao elevar a disponibilidade de água (acréscimos em torno de 125\%), fornecem proteção ao sistema radicular contra desidratação, redução de lixiviação de nutrientes, melhoria da aeração e da drenagem do solo, contribuindo para germinação de sementes e desenvolvimento radicular (AZAMBUJA et al., 2015; NAVROSKI et al., 2015; SAAD et al., 2009).

Neste contexto, o objetivo do trabalho foi a avaliação do potencial do polímero hidrorretentor na melhoria da retenção de água, das características biométricas e da produtividade da cultura do feijão caupi cultivado em solo de textura arenosa.

\section{MATERIAL E MÉTODOS}

O experimento foi conduzido em casa de vegetação na Universidade Federal do Vale do São Francisco, localizada nas coordenadas geográficas: latitude $09^{\circ} 24^{\prime} \mathrm{S}$, longitude $40^{\circ} 31^{\prime} \mathrm{W}$ e altitude de $371 \mathrm{~m}$.

$\mathrm{O}$ delineamento experimental foi em blocos inteiramente casualizados, com sete tratamentos e quatro repetições. Cada parcela foi composta por um vaso de capacidade de $7 \mathrm{~L}$, com solo e a devida quantidade de polímero hidrorretentor ou ausência do mesmo (testemunha). Os tratamentos foram compostos de uma testemunha e seis proporções de polímero hidrorretentor $\left(0,5 \mathrm{~g} \mathrm{~L}^{-1}\right.$ de solo, $0,75 \mathrm{~g}$ $\left.\mathrm{L}^{-1}, 1 \mathrm{~g} \mathrm{~L}^{-1}, 1,5 \mathrm{~g} \mathrm{~L}^{-1}, 2 \mathrm{~g} \mathrm{~L}^{-1} \mathrm{e} 4 \mathrm{~g} \mathrm{~L}^{-1}\right)$. Para melhor homogeneidade na distribuição do polímero, este somente foi hidratado após a incorporação ao solo. Para fins de caracterização e de cálculo de adubação para a cultura do feijão caupi, foram realizadas as análises granulométrica e química do solo, classificado como Planossolo Háplico (Tabelas 1 e 2, respectivamente), conforme Donagema et al. (2011). Essa classe de solo ocupa cerca de 10,5\% da região semiárida nordestina, sendo cultivada, principalmente, com pastagens (SANTOS et al., 2013).

Foram utilizadas sementes de feijão caupi da variedade BRS Tumucumaque, cultivar desenvolvida na Embrapa Meio-Norte, com hábito de crescimento indeterminado, porte semiereto e ciclo de 70 dias (COSTA JÚNIOR, 2015). Foram semeadas quatro sementes por vaso e, após a germinação, realizou-se o desbaste, mantendo-se duas plântulas por vaso.

Tabela 1. Caracterização granulométrica do solo

\begin{tabular}{ccccccc}
\hline Areia Muito Grossa & Areia Grossa & Areia Média & Areia Fina & Areia Muito Fina & Argila & Silte \\
\hline \multicolumn{7}{c}{$\mathrm{g} \mathrm{g}^{-1}$} \\
\hline 8,17 & 10,3 & 29,35 & 24,14 & 12,32 & 0,31 & 15,13 \\
\hline
\end{tabular}

Tabela 2. Caracterização química do solo

\begin{tabular}{|c|c|c|c|c|c|c|c|c|c|c|c|}
\hline $\begin{array}{c}\mathrm{CE} \\
\mathrm{dS} \mathrm{m}^{-1}\end{array}$ & $\mathrm{pH}$ & $\begin{array}{c}\mathrm{MO} \\
\mathrm{g} \mathrm{kg}^{-1}\end{array}$ & 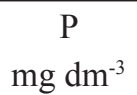 & $\begin{array}{c}\mathrm{C} \\
\mathrm{g} \mathrm{kg}^{-1}\end{array}$ & $\begin{array}{l}\mathrm{K} \\
\ldots \ldots\end{array}$ & $\mathrm{Ca}$ & $\begin{array}{l}\mathrm{Mg} \\
\ldots \mathrm{cmol}\end{array}$ & $\begin{array}{c}\mathrm{Na} \\
\mathrm{dm}^{-3} . .\end{array}$ & $\mathrm{S}$ & $\begin{array}{l}\text { CTC } \\
\ldots \ldots . .\end{array}$ & $\begin{array}{l}\mathrm{V} \\
\%\end{array}$ \\
\hline 0,56 & 6,40 & 6,40 & 12,00 & 3,70 & 0,31 & 2,50 & 1,50 & 0,06 & 4,37 & 6,29 & 69,47 \\
\hline
\end{tabular}

*CE - condutividade elétrica; $\mathrm{MO}$ - matéria orgânica; $\mathrm{P}$ - fósforo; $\mathrm{C}$ - carbono; $\mathrm{K}$ - potássio; $\mathrm{Ca}$ - cálcio; $\mathrm{Mg}$ - magnésio; $\mathrm{Na}$ - Sódio; $\mathrm{S}$ - soma de bases; V - saturação por bases. 
O conteúdo de água no solo, para desenvolvimento da cultura, foi mantido próximo à capacidade de campo $\left(\theta_{\mathrm{CC}}=0,12 \mathrm{~m}^{-3} \mathrm{~m}^{-3}\right)$, mediante informação de evapotranspiração fornecida por Estação Meteorológica, com aplicação manual da lâmina requerida.

Durante o ciclo do feijão caupi, foram avaliados o diâmetro do caule e a altura da parte aérea, utilizando paquímetro e régua milimetrada, respectivamente, conforme Bezerra et al. (2014). Ao final do ciclo, foram avaliados: número de vagens por planta $(\mathrm{NV})$; número de grãos por planta (NGP); número de grãos por vaso (NGV); comprimento médio da vagem (CMV); massa média da vagem (MMV); massa de grãos por planta (MGP); comprimento radicular (CR) e produtividade. Após as avaliações, as partes aérea e radicular foram secas em estufa de circulação forcada a $65^{\circ} \mathrm{C}$ por 72 horas, para determinação das massas secas da raiz (MSR) e da parte aérea (MSPA). Além disso, a massa seca total (MST) foi obtida por meio do somatório da MSR e da MSPA. O peso da biomassa seca por centímetro de raiz, ou seja, a densidade de biomassa (DB) do sistema radicular, expressa em miligramas por centímetro $\left(\mathrm{mg} \mathrm{cm}^{-1}\right)$, foi resultante da razão entre a massa seca radicular (MSR) e o comprimento da raiz, de acordo com Bezerra et al. (2014).

Com os dados obtidos, elaborou-se um mapa de superfície com auxílio do software Surfer 10 e realizou-se comparação de custos para produção de feijão caupi ao aplicar as diferentes proporções do polímero hidrorretentor.

Para a realização das análises de solo, ao final do ciclo da cultura, foram retiradas amostras deformadas para determinação da umidade e da curva de retenção de água nas tensões de $10 ; 30 ; 50$; 100; 300; 500 e $1500 \mathrm{kPa}$ pelo método da câmara de Richards (DONAGEMA et al., 2011). Os valores de retenção de água foram ajustados pelo modelo de Van Genuchten (1980) para elaboração da curva característica da água do solo.

Os resultados analíticos foram submetidos à análise descritiva e à análise de variância, com as médias sendo comparadas pelo teste de Scott Knott $(p<0,05)$ com auxílio do software estatístico ASSISTAT beta 7.7.

\section{RESULTADOS E DISCUSSÃO}

A aplicação de maiores proporções do polímero hidrorretentor ao solo favoreceu o desenvolvimento do diâmetro do caule e altura da planta (Tabela 3 e Figura 1), que ocorreu até os 55 e 50 primeiros dias após a semeadura (DAS), respectivamente. Após esses períodos, não houve diferença significativa nas variáveis avaliadas, pois a planta atinge o clímax produtivo e começa a finalizar seu ciclo (MOURA et al., 2012).

Tabela 3. Estatística descritiva do diâmetro médio do caule, altura média e densidade de biomassa do feijão caupi em função das proporções de polímero hidrorretentor.

\begin{tabular}{|c|c|c|c|c|c|c|c|}
\hline Parâmetros & T0 & $\mathrm{T} 1$ & $\mathrm{~T} 2$ & $\mathrm{~T} 3$ & $\mathrm{~T} 4$ & $\mathrm{T5}$ & T6 \\
\hline \multicolumn{8}{|c|}{ Diâmetro (cm) } \\
\hline Média & 0,77 & 0,87 & 1,03 & 0,93 & 1,03 & 1,17 & 1,13 \\
\hline Mediana & 0,80 & 0,90 & 1,00 & 1,00 & 1,00 & 1,10 & 1,20 \\
\hline Desvio Padrão & 0,06 & 0,06 & 0,06 & 0,21 & 0,15 & 0,12 & 0,12 \\
\hline $\mathrm{CV}(\%)$ & 7,80 & 6,90 & 5,82 & 22,58 & 14,56 & 10,26 & 10,61 \\
\hline Mínimo & 0,70 & 0,80 & 1,00 & 0,70 & 0,90 & 1,10 & 1,00 \\
\hline Máximo & 0,80 & 0,90 & 1,10 & 1,10 & 1,20 & 1,30 & 1,20 \\
\hline \multicolumn{8}{|c|}{ Altura $(\mathrm{cm})$} \\
\hline Média & 25,00 & 36,67 & 52,00 & 70,67 & 84,00 & 117,00 & 82,67 \\
\hline Mediana & 25,00 & 37,00 & 46,00 & 82,00 & 89,00 & 118,00 & 84,00 \\
\hline Desvio Padrão & 3,00 & 13,50 & 22,60 & 36,35 & 29,82 & 21,52 & 18,04 \\
\hline $\mathrm{CV}(\%)$ & 12,00 & 36,81 & 43,46 & 51,44 & 35,50 & 18,39 & 21,82 \\
\hline Mínimo & 22,00 & 23,00 & 33,00 & 30,00 & 52,00 & 95,00 & 64,00 \\
\hline Máximo & 28,00 & 50,00 & 77,00 & 100,00 & 111,00 & 138,00 & 100,00 \\
\hline \multicolumn{8}{|c|}{ Densidade de biomassa $\left(\mathrm{mg} \mathrm{cm}^{-1}\right)$} \\
\hline Média & 0,55 & 0,39 & 0,48 & 0,54 & 0,56 & 0,55 & 1,00 \\
\hline Mediana & 0,55 & 0,39 & 0,48 & 0,54 & 0,56 & 0,55 & 1,00 \\
\hline Desvio Padrão & 0,02 & 0,08 & 0,04 & 0,02 & 0,02 & 0,01 & 0,01 \\
\hline $\mathrm{CV}(\%)$ & 3,64 & 20,51 & 8,33 & 3,70 & 3,57 & 1,82 & 1,00 \\
\hline Mínimo & 0,54 & 0,31 & 0,45 & 0,52 & 0,54 & 0,53 & 0,99 \\
\hline Máximo & 0,57 & 0,47 & 0,52 & 0,56 & 0,57 & 0,56 & 1,01 \\
\hline
\end{tabular}

*T0 - $0 \mathrm{~g} \mathrm{~L}^{-1}, \mathrm{~T} 1-0,5 \mathrm{~g} \mathrm{~L}^{-1}, \mathrm{~T} 2-0,75 \mathrm{~g} \mathrm{~L}^{-1}, \mathrm{~T} 3-1,0 \mathrm{~g} \mathrm{~L}^{-1}, \mathrm{~T} 4-1,5 \mathrm{~g} \mathrm{~L}^{-1}, \mathrm{~T} 5-2,0 \mathrm{~g} \mathrm{~L}^{-1} \mathrm{e} \mathrm{T} 6-4,0 \mathrm{~g} \mathrm{~L}^{-1}$. CV-coeficiente de variação. 
Para a avaliação do diâmetro e altura média, percebe-se que os valores variaram de 0,70 a 1,30 e 22,00 a 138,00 , respectivamente, com valores mínimos na testemunha e máximos na proporção 2,0 $\mathrm{g} \mathrm{L}^{-1}$. A densidade da biomassa apresentou comportamento diferente, com menor valor na proporção $0,5 \mathrm{~g} \mathrm{~L}^{-1} \mathrm{e}$ maior na proporção $4,0 \mathrm{~g} \mathrm{~L}^{-1}$.

Ao ajustar os dados de diâmetro do caule, altura de planta e densidade da biomassa, a regressão polinomial quadrática se constitui o modelo de melhor ajuste, proporcionando coeficientes de determinação superiores a $87 \%$ e evidenciando a tendência da ocorrência de maiores diâmetros e alturas da planta ao elevar a proporção do polímero (Figura 1).

As equações de regressão encontradas possibilitaram, através da obtenção dos pontos de máximo e de mínimo, a determinação das proporções de hidrorretentor mais e menos promissoras, as quais promoveriam a máxima e a mínima eficiência técnica.
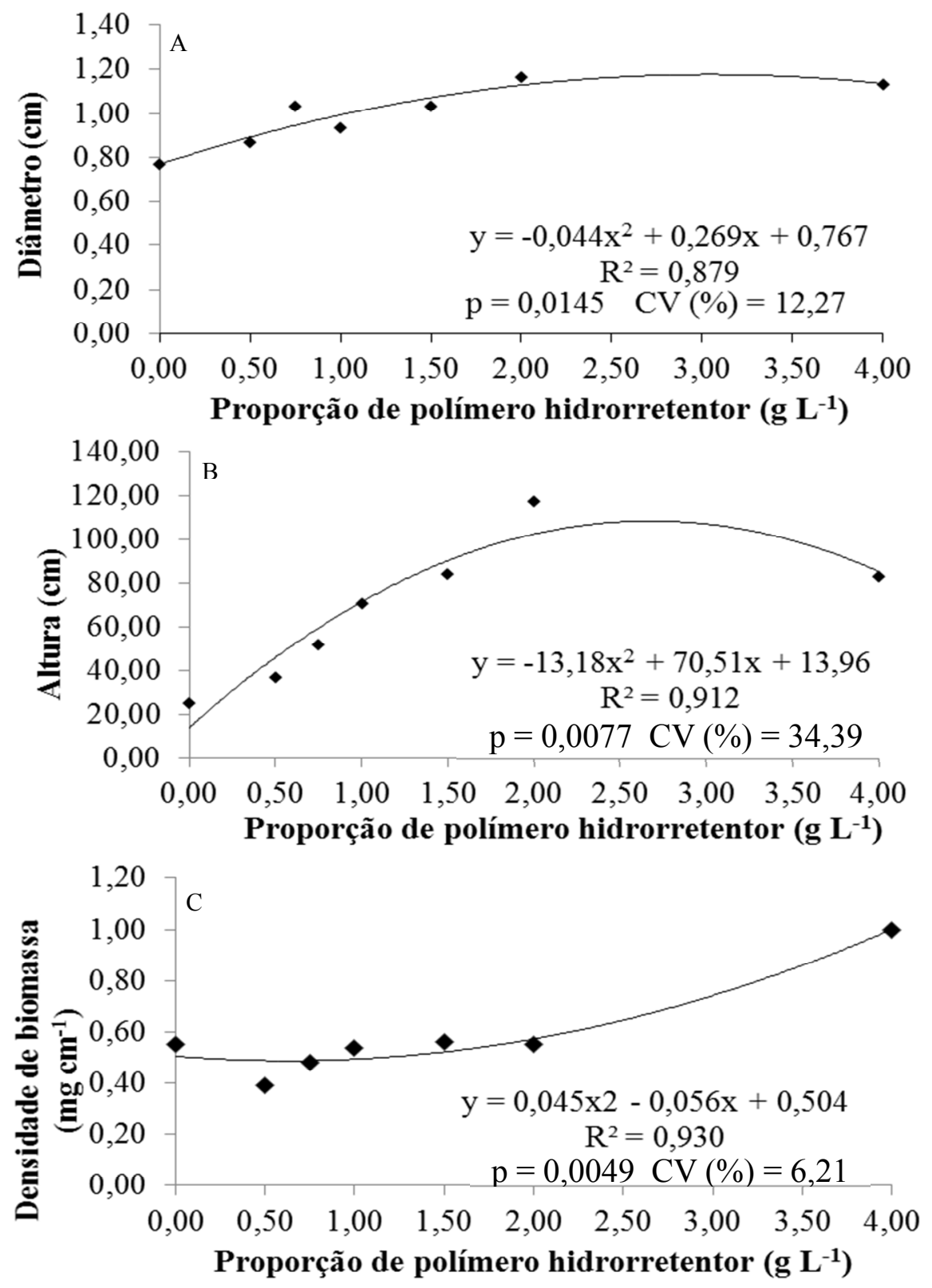

Figura 1. Diâmetro médio do caule (A), Altura média (B) e Densidade de biomassa (C) do feijão caupi em função das proporções de polímero hidrorretentor. 
A testemunha e a aplicação da proporção 2,00 $\mathrm{g} \mathrm{L}^{-1}$ do polímero hidrorretentor ao solo promoveram a obtenção do menor e do maior valor, respectivamente, para as variáveis diâmetro do caule e altura da planta (Figuras 1A e 1B), porém ao determinar a proporção de máxima eficiência técnica (MET), observa-se que os valores mais elevados seriam obtidos nas proporções de $3,04 \mathrm{~g}$ $\mathrm{L}^{-1}$ e $2,67 \mathrm{~g} \mathrm{~L}^{-1}$, respectivamente. Resultados semelhantes foram encontrados por Navroski et al. (2015), que ao avaliar o desenvolvimento de mudas de Eucalyptus dunnii observaram aumento quadrático no diâmetro do caule e na altura ao elevar a proporção do polímero hidrorretentor, com MET nas doses de 4,4g L-1 $(2,06 \mathrm{~cm})$ e $6,3 \mathrm{~g} \mathrm{~L}^{-1}(25$ $\mathrm{cm})$, respectivamente.

A regressão polinomial quadrática, obtida para a variável altura da planta, também possibilitou observar que proporções superiores à máxima eficiência técnica $\left(2,67 \mathrm{~g} \mathrm{~L}^{-1}\right)$ tenderão a diminuir a altura das plantas, evidenciando que adicionar polímero hidrorretentor em proporções maiores que a da MET não promoverão maior desenvolvimento da cultura.

Quando analisado o sistema radicular, percebese que a aplicação do polímero proporcionou um aumento quadrático dessa variável, com equação indicando que a proporção de $0,62 \mathrm{~g} \mathrm{~L}^{-1}$ promoveria a menor eficiência técnica, enquanto que a maior proporção utilizada $\left(4 \mathrm{~g} \mathrm{~L}^{-1}\right)$ proporcionou uma biomassa mais densa (Figura $1 \mathrm{C}$ ), característica desejável, pois a raiz auxilia no desenvolvimento da planta, ao ser responsável pela absorção de água e de nutrientes (CABREIRA et al., 2017). Esse incremento da densidade radicular pode estar relacionado à otimização de propriedades físicas e químicas do solo pela adição de polímero hidrorretentor (AZAMBUJA et al., 2015).

A dinâmica de nutrientes pode ser condicionada pela umidade do solo, com baixos teores de água, desfavorecendo a absorção de nutrientes (SANTANA et al., 2015). Sabe-se também que o nitrogênio e o fósforo são elementos essenciais ao arranque inicial das plantas, sendo nutrientes altamente requeridos no estádio inicial(CABREIRA et al., 2017). Desta forma, a aplicação de polímero hidrorretentor favoreceu maior disponibilidade de água no solo (Figura 2) e, provavelmente, favoreceu maior absorção desses nutrientes, via água, corroborando com o desenvolvimento do diâmetro do caule e com a altura da cultura.

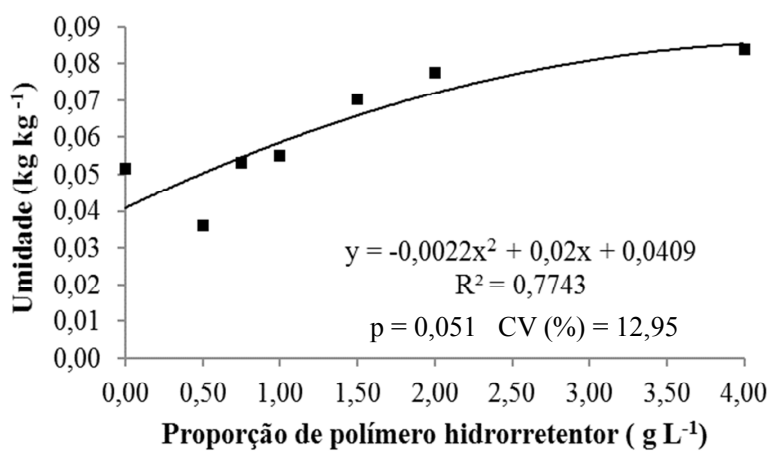

Figura 2. Teores de umidade em função das dosagens de polímero hidrorretentor.

A adição do polímero hidrorretentor resultou em incremento quadrático na retenção de água no solo, com as proporções $0,50 \mathrm{~g} \mathrm{~L}^{-1}$ e $4,00 \mathrm{~g}$ $\mathrm{L}^{-1}$, apresentando o menor e o maior conteúdo de água no solo, respectivamente. E, através da regressão, observa-se que a proporção de $4,54 \mathrm{~g} \mathrm{~L}^{-1}$ conferiria ao solo máxima umidade $\left(0,09 \mathrm{~kg} \mathrm{~kg}^{-1}\right)$. Este comportamento pode ser justificado devido à capacidade do polímero hidrorretentor de absorver água em mais de 100 vezes a sua massa, liberando-a controladamente (NAVROSKI et al., 2015).

O teor de água retido no solo após aplicação de tensões na Câmara de Richards (10 a 1500kPa) está representado na Figura 3 e na Tabela 4.

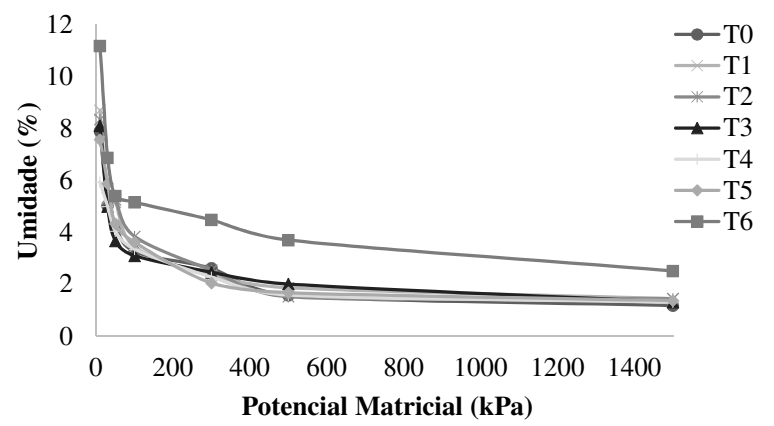

$\mathrm{T} 0-0 \mathrm{~g} \mathrm{~L}^{-1}, \mathrm{~T} 1-0,5 \mathrm{~g} \mathrm{~L}^{-1}, \mathrm{~T} 2-0,75 \mathrm{~g} \mathrm{~L}^{-1}, \mathrm{~T} 3-1,0 \mathrm{~g} \mathrm{~L}^{-1}, \mathrm{~T} 4-1,5 \mathrm{~g}$ $\mathrm{L}^{-1}, \mathrm{~T} 5-2,0 \mathrm{~g} \mathrm{~L}^{-1} \mathrm{e}$ T6 $-4,0 \mathrm{~g} \mathrm{~L}^{-1}$.

Figura 3. Teor de água no solo após aplicação de tensões na Câmara de Richards. 
Observa-se que à medida que se eleva o potencial matricial, menor é a capacidade do solo de reter água. No entanto, apesar de seguir essa tendência, a maior proporção de polímero hidrorretentor conferiu ao solo maior capacidade de retenção de água e, consequentemente, aumentou a disponibilidade para utilização pela planta, possibilitando a realização de turnos de rega mais espaçados, reduzindo custos com eletricidade e água. Resultado semelhante foi encontrado por Navroski (2013), que observou maior retenção de água no solo ao aplicar a maior proporção do polímero $\left(6,00 \mathrm{~g} \mathrm{~L}^{-1}\right)$, evidenciando o potencial dessa substância em manter água no sistema.

Dentre as características produtivas avaliadas percebe-se que a adição da maior proporção de polímero hidrorretentor favoreceu maior produção de número de vagens $(\mathrm{NV})$, além de, nas três maiores proporções, ocorrer incremento no número de grãos por planta (NGP) (Tabela 5).

Como em estudo realizado por Lopes (2016), utilizando polímero hidrorretentor na cultura do feijão caupi, a aplicação desse produto promoveu, com significância, uma maior produção de vagens em relação à testemunha.

Para as variáveis comprimento médio das vagens (CMV) e massa média das vagens (MMV), a testemunha diferiu, significativamente, de todos os tratamentos, exceto da aplicação de $4,00 \mathrm{~g}$ $\mathrm{L}^{-1}$, enquanto que essa diferença significativa para massa de grãos por planta (MGP) limitouse às proporções $2,00 \mathrm{~g} \mathrm{~L}^{-1}$ e $4,00 \mathrm{~g} \mathrm{~L}^{-1}$. Esses resultados evidenciam que a utilização de polímero hidrorretentor melhora características produtivas do feijão caupi e podem estar relacionados com a possível maior disponibilidade de água e, consequentemente, maior facilidade de absorção de nutrientes pelas plantas.

Tabela 4. Teor de água no solo após aplicação de tensões na Câmara de Richards

\begin{tabular}{cccccccc}
\hline Proporções & $10 \mathrm{kPa}$ & $30 \mathrm{kPa}$ & $50 \mathrm{kPa}$ & $100 \mathrm{kPa}$ & $300 \mathrm{kPa}$ & $500 \mathrm{kPa}$ & $1500 \mathrm{kPa}$ \\
\hline $0,00 \mathrm{~g} \mathrm{~L}^{-1}$ & $7,90 \mathrm{a}$ & $5,02 \mathrm{~b}$ & $4,24 \mathrm{a}$ & $3,25 \mathrm{~b}$ & $2,61 \mathrm{~b}$ & $1,57 \mathrm{~b}$ & $1,17 \mathrm{~b}$ \\
$0,50 \mathrm{~g} \mathrm{~L}^{-1}$ & $8,70 \mathrm{a}$ & $5,30 \mathrm{~b}$ & $5,16 \mathrm{a}$ & $3,44 \mathrm{~b}$ & $2,34 \mathrm{~b}$ & $1,86 \mathrm{~b}$ & $1,44 \mathrm{~b}$ \\
$0,75 \mathrm{~g} \mathrm{~L}^{-1}$ & $8,34 \mathrm{a}$ & $5,33 \mathrm{~b}$ & $5,25 \mathrm{a}$ & $3,84 \mathrm{~b}$ & $2,54 \mathrm{~b}$ & $1,51 \mathrm{~b}$ & $1,44 \mathrm{~b}$ \\
$1,00 \mathrm{~g} \mathrm{~L}^{-1}$ & $8,10 \mathrm{a}$ & $4,99 \mathrm{~b}$ & $3,66 \mathrm{a}$ & $3,10 \mathrm{~b}$ & $2,46 \mathrm{~b}$ & $2,00 \mathrm{~b}$ & $1,31 \mathrm{~b}$ \\
$1,50 \mathrm{~g} \mathrm{~L}^{-1}$ & $5,93 \mathrm{~b}$ & $4,99 \mathrm{~b}$ & $4,04 \mathrm{a}$ & $3,34 \mathrm{~b}$ & $2,27 \mathrm{~b}$ & $1,58 \mathrm{~b}$ & $1,31 \mathrm{~b}$ \\
$2,00 \mathrm{~g} \mathrm{~L}^{-1}$ & $7,57 \mathrm{a}$ & $5,87 \mathrm{~b}$ & $4.32 \mathrm{a}$ & $3,61 \mathrm{~b}$ & $2,04 \mathrm{~b}$ & $1,67 \mathrm{~b}$ & $1,36 \mathrm{~b}$ \\
$4,00 \mathrm{~g} \mathrm{~L}^{-1}$ & $11,18 \mathrm{a}$ & $6,87 \mathrm{a}$ & $5,40 \mathrm{a}$ & $5,16 \mathrm{a}$ & $4,48 \mathrm{a}$ & $3,70 \mathrm{a}$ & $2,51 \mathrm{a}$ \\
$\mathrm{CV} \mathrm{( \% )}$ & 16,78 & 10,39 & 18,60 & 16,13 & 18,15 & 28,28 & 18,31 \\
\hline
\end{tabular}

*Médias da coluna seguidas de letras diferentes diferem entre si pelo teste Scott Knott a 5\% de probabilidade. CV-coeficiente de variação.

Tabela 5. Características produtivas e morfológicas do feijão caupi em função das dosagens de polímero hidrorretentor

\begin{tabular}{cccccccc}
\hline Proporções & NV & NGV & NGP & CMV (cm) & MMV $(\mathrm{g})$ & MGP $(\mathrm{g})$ & MST $(\mathrm{g})$ \\
\hline $0,00 \mathrm{~g} \mathrm{~L}^{-1}$ & $7,00 \mathrm{~b}$ & $6,40 \mathrm{c}$ & $44,00 \mathrm{~b}$ & $15,67 \mathrm{~b}$ & $2,21 \mathrm{~b}$ & $11,25 \mathrm{~b}$ & $38,14 \mathrm{a}$ \\
$0,50 \mathrm{~g} \mathrm{~L}^{-1}$ & $5,67 \mathrm{~b}$ & $8,93 \mathrm{~b}$ & $50,67 \mathrm{a}$ & $18,05 \mathrm{a}$ & $2,84 \mathrm{a}$ & $11,11 \mathrm{~b}$ & $43,08 \mathrm{a}$ \\
$0,75 \mathrm{~g} \mathrm{~L}^{-1}$ & $4,00 \mathrm{~b}$ & $8,92 \mathrm{~b}$ & $36,50 \mathrm{~b}$ & $18,62 \mathrm{a}$ & $3,06 \mathrm{a}$ & $9,13 \mathrm{~b}$ & $44,09 \mathrm{a}$ \\
$1,00 \mathrm{~g} \mathrm{~L}^{-1}$ & $3,00 \mathrm{~b}$ & $8,62 \mathrm{~b}$ & $22,50 \mathrm{~b}$ & $20,31 \mathrm{a}$ & $3,15 \mathrm{a}$ & $5,43 \mathrm{c}$ & $42,05 \mathrm{a}$ \\
$1,50 \mathrm{~g} \mathrm{~L}^{-1}$ & $5,50 \mathrm{~b}$ & $10,58 \mathrm{a}$ & $58,50 \mathrm{a}$ & $19,31 \mathrm{a}$ & $3,09 \mathrm{a}$ & $11,49 \mathrm{~b}$ & $62,44 \mathrm{a}$ \\
$2,00 \mathrm{~g} \mathrm{~L}^{-1}$ & $5,33 \mathrm{~b}$ & $10,71 \mathrm{a}$ & $56,67 \mathrm{a}$ & $19,75 \mathrm{a}$ & $3,45 \mathrm{a}$ & $14,25 \mathrm{a}$ & $51,77 \mathrm{a}$ \\
$4,00 \mathrm{~g} \mathrm{~L}^{-1}$ & $10,67 \mathrm{a}$ & $7,43 \mathrm{c}$ & $70,00 \mathrm{a}$ & $16,76 \mathrm{~b}$ & $2,28 \mathrm{~b}$ & $16,58 \mathrm{a}$ & $67,27 \mathrm{a}$ \\
$\mathrm{CV}(\%)$ & 24,26 & 9,63 & 20,83 & 8,65 & 13,31 & 19,01 & 23,88 \\
\hline
\end{tabular}

NV - número de vagens por planta; NGV - número de grãos por vagem; NGP - número de grãos por planta; CMV - comprimento médio da vagem; MMV - massa média da vagem; MST - massa seca total da planta. *Médias da coluna seguidas de letras diferentes, diferem entre si pelo teste Scott Knott a 5\% de probabilidade. CV-coeficiente de variação. 
A Tabela 5 também aponta que a massa seca total (MST) não apresentou diferença significativa entre os tratamentos. Porém, os tratamentos com as três maiores proporções $\left(1,50 ; 2,00 \mathrm{e} 4,00 \mathrm{~g} \mathrm{~L}^{-1}\right)$ apresentaram MST de 39, 26 e 43\% superior em relação à testemunha, respectivamente, indicando que a aplicação do polímero favoreceu o maior desenvolvimento da cultura.

Esse resultado difere do encontrado por Mews et al. (2015) em estudo sobre a utilização de hidrorretentor na produção de mudas de ipê opa (Handroanthus ochraceus (Cham) Mattos), que encontraram matéria seca com peso significativamente mais elevado ao aplicar a maior proporção de polímero hidrorretentor $(4,00 \mathrm{~g})$.

A divergência entre o resultado obtido e o encontrado em literatura pode ser explicada pelo elevado coeficiente de variação $(23,88 \%)$, expressando a imprecisão nos dados obtidos. Isso pode ser atribuído à soma dos erros das variáveis utilizadas (MSR e MSPA) para a obtenção desse valor.

Comparando a Figura 2 e a Tabela 5, percebese, através do mapa de superfície (Figura 4), que ao se elevar a proporção do polímero e, consequentemente, maior ser a retenção de água ao solo, maior foi a produtividade de grãos. Esse resultado pode estar relacionado ao maior teor de água disponível para absorção pelas plantas e, por conseguinte, de nutrientes, favorecendo a maior produtividade da cultura.

Lopes (2016) obteve resultados que corroboram com o encontrado. Ao avaliar concentrações diferentes de polímero hidrorretentor na produtividade de feijão caupi, a maior proporção $\left(15,8 \mathrm{~kg} \mathrm{ha}^{-1}\right)$ desse produto elevou a produtividade em $58 \%$ em relação à testemunha.

Ao calcular a produtividade da cultura, percebese que a utilização de polímero hidrorretentor favoreceu maior produtividade do feijão, sendo que as proporções de $2,00 \mathrm{~g} \mathrm{~L}^{-1}$ e $4,00 \mathrm{~g} \mathrm{~L}^{-1}$ foram $26 \mathrm{e}$ $47 \%$ significativamente superiores à concentração de $0 \mathrm{~g} \mathrm{~L}^{-1}$, respectivamente (Tabela 6).

Tabela 6. Produtividade do feijão caupi em função das dosagens de polímero hidrorretentor.

\begin{tabular}{cc}
\hline Proporções & Produtividade (kg ha-1) \\
\hline $0,00 \mathrm{~g} \mathrm{~L}-1$ & $1103,04 \mathrm{~b}$ \\
$0,50 \mathrm{~g} \mathrm{~L}-1$ & $1089,26 \mathrm{~b}$ \\
$0,75 \mathrm{~g} \mathrm{~L}-1$ & $895,13 \mathrm{~b}$ \\
$1,00 \mathrm{~g} \mathrm{~L}-1$ & $532,66 \mathrm{c}$ \\
$1,50 \mathrm{~g} \mathrm{~L}-1$ & $1126,76 \mathrm{~b}$ \\
$2,00 \mathrm{~g} \mathrm{~L}-1$ & $1397,22 \mathrm{a}$ \\
$4,00 \mathrm{~g} \mathrm{~L}-1$ & $1626,04 \mathrm{a}$ \\
CV (\%) & 19,01 \\
\hline
\end{tabular}

Médias seguidas de letras diferentes diferem entre si pelo teste Scott Knott a 5\% de probabilidade. CV-coeficiente de variação.

Considerando que o custo de $1 \mathrm{~kg}$ de polímero hidrorretentor foi de $\mathrm{R} \$ 21,50$, estimou-se o custo do produto por hectare, considerando cada proporção utilizada (Tabela 7). Para isso, se considerou a cultura implantada com espaçamento entre linhas de $0,60 \mathrm{~m}$ e entre planta de $0,17 \mathrm{~m}$, totalizando 98039 plantas por hectare.

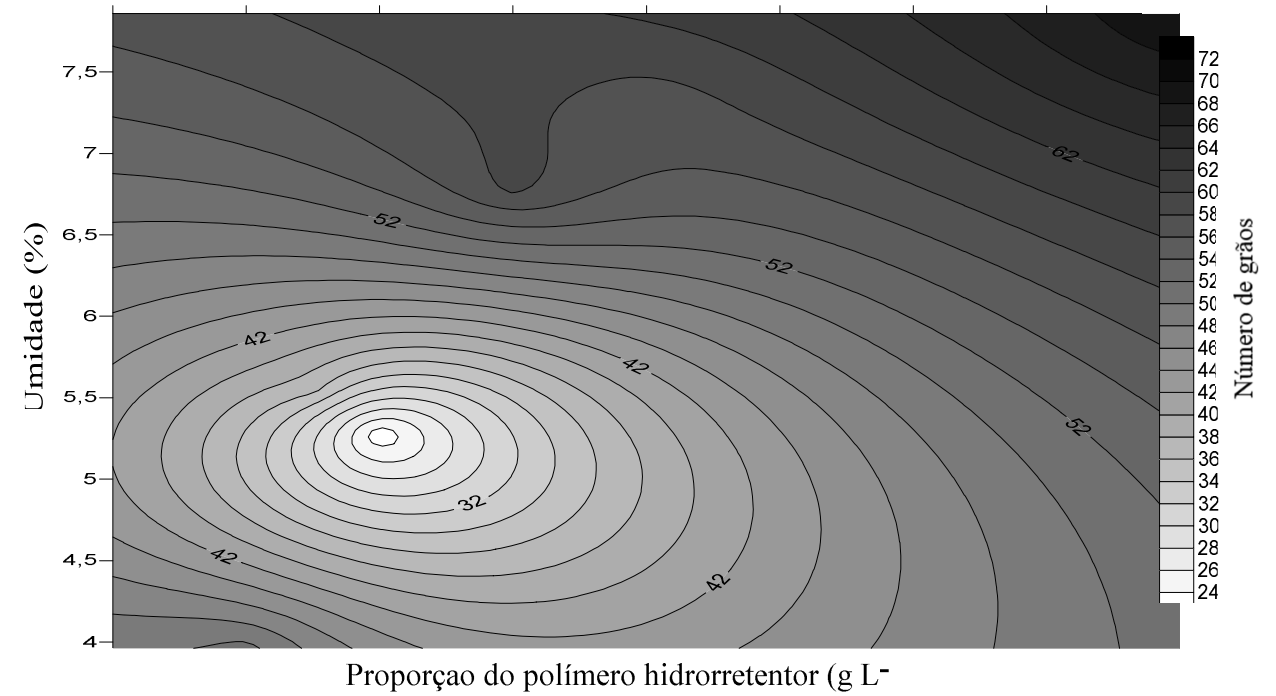

Figura 4. Valor do número de grãos por planta em função das proporções de polímero hidrorretentor e umidade do solo. 
RETENÇÃO DE ÁGUA E DESENVOLVIMENTO DO FEIJÃO CAUPI EM FUNÇÃO DO USO DE POLÍMERO HIDRORRETENTOR...

Tabela 7. Custo da aplicação das diferentes proporções de polímero hidrorretentor para um hectare de plantio.

\begin{tabular}{cccc}
\hline Proporções & $\begin{array}{c}\text { Quantidade aplicada por } \\
\text { planta }(\mathrm{g})\end{array}$ & $\begin{array}{c}\text { Custo por planta } \\
\left(\mathrm{R} \$ \mathrm{~kg}^{-1}\right)\end{array}$ & $\begin{array}{c}\text { Custo polímero } \\
\left(\mathrm{R} \$ \mathrm{ha}^{-1}\right)\end{array}$ \\
\hline $0,00 \mathrm{~g} \mathrm{~L}^{-1}$ & 0,000 & 0,000 & 0,00 \\
$0,50 \mathrm{~g} \mathrm{~L}^{-1}$ & 0,250 & 0,005 & 490,19 \\
$0,75 \mathrm{~g} \mathrm{~L}^{-1}$ & 0,375 & 0,008 & 784,31 \\
$1,00 \mathrm{~g} \mathrm{~L}^{-1}$ & 0,500 & 0,011 & 1078,43 \\
$1,50 \mathrm{~g} \mathrm{~L}^{-1}$ & 0,750 & 0,016 & 1568,62 \\
$2,00 \mathrm{~g} \mathrm{~L}^{-1}$ & 1,000 & 0,021 & 2058,82 \\
$4,00 \mathrm{~g} \mathrm{~L}^{-1}$ & 2,000 & 0,043 & 4215,68 \\
\hline
\end{tabular}

Observa-se o baixo custo por planta, tornando o hidrogel uma alternativa às produções em sequeiro e irrigado, uma vez que, segundo Bernardi et al. (2012), a utilização desse produto pode reduzir o número de irrigação, além de amortizar em até $20 \%$ a adubação rotineira.

Para aplicar a dosagem de $2 \mathrm{~g}$ de polímero hidrorretentor por planta em 1 ha, seria necessário um investimento de $\mathrm{R} \$ 2058,82$, podendo proporcionar incrementos de $50 \%$ no teor de umidade do solo e de $26 \%$ na produtividade do feijão caupi.

Segundo CEASA Pernambuco (CEASAPE, 2018), o valor de venda de uma saca de $60 \mathrm{~kg}$ de feijão caupi é de $\mathrm{R} \$ 154,00$, obtendo-se lucro de $\mathrm{R} \$ 3585,12 \mathrm{ha}^{-1}$. No entanto, devem-se considerar gastos com aquisição do hidrogel ( $\left.\mathrm{R} \$ 2058,82 \mathrm{ha}^{-1}\right)$ e com aquisição de insumos.

Através dos resultados da análise química do solo, observa-se que a realização de adubação de manutenção é suficiente para fornecer os nutrientes requeridos pelas plantas, exigindo apenas a aplicação de $44 \mathrm{~kg}$ de ureia, $222,2 \mathrm{~kg}$ de superfosfato simples e $50 \mathrm{~kg}$ de cloreto de potássio, resultando em um investimento aproximado de $\mathrm{R} \$ 1380,13$ $\mathrm{ha}^{-1}$. Nestas condições, o lucro do produtor seria de $\mathrm{R} \$ 146,11$ ha $^{-1}$, corroborando em baixo retorno e tornando a aplicação do polímero hidrorretentor uma opção pouco viável.

No entanto, sabe-se que o hidrogel apresenta vida útil de 1 a 5 anos, dependendo do manejo do solo (SAAD et al., 2009), e que o feijão caupi possui ciclo de 70 dias (COSTA JÚNIOR, 2015), possibilitando a realização de mais de dois plantios por ano, sem necessidade de aplicação do polímero hidrorretentor, extinguindo, assim, os gastos com o mesmo e, consequentemente, elevando o lucro para $\mathrm{R} \$ 2204,99 \mathrm{ha}^{-1}$.

\section{CONCLUSÕES}

- A utilização do polímero hidrorretentor como condicionador do solo possibilitou melhoria na retenção de água no solo e em grande parte das propriedades morfológicas e produtivas do feijão caupi.

- Dentre as dosagens avaliadas, as proporções de 1,50; 2,00 e 4,00g de polímero hidrorretentor por litro de solo se apresentaram como as que mais favoreceram ao desenvolvimento vegetal.

- Para melhor escolha de qual proporção utilizar, torna-se necessária uma avaliação dos custos envolvidos no sistema de produção adotado e no sistema que se deseja implantar, para haver uma utilização racional e eficiente dos recursos disponíveis.

\section{AGRADECIMENTOS}

À FAPESB pelo apoio financeiro e à UNIVASF por disponibilizar o Laboratório de Física dos Solos e de Irrigação para realização das análises.

\section{REFERÊNCIAS BIBLIOGRÀFICAS}

AZAMBUJA, L.O.; BENETT, C.G.S.; BENETT, K.S.S.; COSTA, E. Produtividade da abobrinha 'Caserta' em função do nitrogênio e gel hidrorretentor. Científica, Jaboticabal, v.43, n.4, p.353-358, 2015. 
BERNARDI, M.R.; SPEROTTO JUNIOR, M.; DANIEL, O.; VITORINO, A.C.T. Crescimento de mudas de Corymbia citriodora em função do uso de hidrogel e adubação. Cerne, Lavras, v.18, n.1, p.67-74, 2012.

BEZERRA, M.A.F.; OLIVEIRA, F.A. de; BEZERRA, F.T.C., PEREIRA, W.E.; SILVA, S.A. da. Cultivo de feijão-caupi em Latossolos sob o efeito residual da adubação fosfatada. Revista Caatinga, Mossoró, v.27, n.1, p.109-115, 2014.

CABREIRA, G.V.; LELES, P.S. dos S.; ALONSO, J.M.; ABREU, A.H.M. de; SANTOS, G.R. dos. Biossólido como componente de substrato para produção de mudas florestais. Floresta, Curitiba, v.47, n.2, p.167-176, 2017.

CARVALHO, R.P.; CRUZ, M.C.M.; MARTINS, L.M. Frequência de irrigação utilizando polímero hidroabsorvente na produção de mudas de maracujazeiro-amarelo. Revista Brasileira de Fruticultura, Jaboticabal, v.35, n.2, p.518-526, 2013.

CEASAPE - Centro de Abastecimento e Logística de Pernambuco. Cotação de preço. Disponível em: <http://www.ceasape.org.br/cotacao/cereaise-diversos?data $=06 \% 2 \mathrm{~F} 06 \% 2 \mathrm{~F} 2018>$. Acesso em 03 de julho de 2018 .

CONTE, A.M.; MAIA, G.M.; SOUZA, J.A. de; MANFIO, F.L.A. Crescimento inicial de cafeeiro com uso de polímero hidroabsorvente e diferentes intervalos de rega. Coffee Science, Lavras, v.9, n.4, p.465-471, 2014.

COSTA JÚNIOR, M.J.N. Desempenho agronômico do feijão-caupi sob diferentes lâminas de irrigação e espaçamentos entre fileiras. 2015. 71f. Dissertação (Mestrado em Agronomia) - Universidade Federal do Piauí, Teresina, 2015.

COUTINHO, P.W.R.; SILVA, D.M.S. da; SALDANHA, E.C.M.; OKUMURA, R.S.; SILVA JÚNIOR, M.L. da. Doses de fósforo na cultura do feijão-caupi na região nordeste do Estado do
Pará. Revista Agro@mbiente On-line, Boa Vista, v.8, n.1, p.66-73, 2014.

DONAGEMA， G.K.; CAMPOS， D.V.B.de; CALDERANO, S.B.; TEXEIRA, W.G.; VIANA, J.H.M. Manual de métodos de análise de solo. Rio de Janeiro: EMBRAPA-CNPS, 2011. 230p.

LOPES, M.B.S. Hidrogéis como alternativa no aumento da capacidade de retenção de água no solo para cultura da soja e do feijão caupi. 2016. 66f. Tese (Doutorado em Produção Vegetal) Universidade Federal do Tocantins, Gurupi, 2016.

MEWS, C.L.; SOUSA, J.R.L. de; AZEVEDO, G.T.O.S.; SOUZA, A.M. Efeito do Hidrogel e Ureia na Produção de Mudas de Handroanthus ochraceus (Cham.) Mattos. Floresta e Ambiente, Seropédica, v.22, n.1, p.107-116, 2015.

MOURA, J.Z.; PÁDUA, L.E.M.; MOURA, S.G.; TORRES, J.S.; SILVA, P.R.R. Escala de desenvolvimento fenológico e exigência térmica associada a graus-dia do feijão-caupi. Revista Caatinga, Mossoró, v.25, n.3, p.66-71, 2012.

NAVROSKI, M.C. Hidrogel como condicionador de substrato para produção de mudas de Eucalyptus dunnii Maiden. 2013. 224f. Tese (Doutorado emEngenhariaFlorestal)-Universidade Federal de Santa Maria, Santa Maria, 2013.

NAVROSKI, M.; ARAUJO, M.M.; REINIGER, L.R.S.; MUNIZ, M.F.B.; PEREIRA, O.M. de Influência do hidrogel no crescimento e no teor de nutrientes das mudas de Eucalyptus dunnii. Floresta, Curitiba, v.45, n.2, p.315-328, 2015.

SAAD, J.C.C; LOPES, J.L.W.; SANTOS, T.A. dos. Manejo hídrico em viveiro e uso de hidrogel na sobrevivência pós-plantio de Eucalyptus urograndis em dois solos diferentes. Revista Engenharia Agrícola, Jaboticabal, v.29, n.3, p.404-411, 2009.

SANTANA, H.M.P.; SANO, E.E.; OLIVEIRA JÚNIOR, M.O.; LACERDA, M.P.C.; MALAQUIAS, J.V. Relação entre atributos físicos 
RETENÇÃO DE ÁGUA E DESENVOLVIMENTO DO FEIJÃO CAUPI EM FUNÇÃO DO USO DE POLÍMERO HIDRORRETENTOR...

e químicos dos solos e a produtividade de capim dourado na Região do Jalapão, TO. Revista Brasileira de Ciência do Solo, Viçosa, v.39, n.4, p.1172-1180, 2015.

SANTOS, H.T.; CARVALHO, D.F.; SOUZA, C.F.; MEDICI, L.O. Cultivo de alface em solos com hidrogel utilizando irrigação automatizada. Revista Engenharia Agrícola, Jaboticabal, v.35, n.5, p.852-862, 2015.

SANTOS, J.L.D.; ALMEIDA, J.N.; SANTOS, A.C. Caracterização física e química de um Planossolo localizado no semiárido baiano. Revista Agropecuária Científica no Semiárido, v.9, n.3, p.13-17, 2013.

SOUSA, A.M.; NETO, A.B.; PINHEIRO, J.I.; SILVA, V.B.; NOGUEIRA, D.B. Comportamento dos preços de milho e feijão caupi no mercado do estado do Ceará. Revista Verde de Agroecologia e
Desenvolvimento Sustentável, Pombal, v.10, n.5, p.1-8, 2015.

TAGLIAFERRE, C.; SANTOS, T.J.; SANTOS, L.D.C.; NETO, I.J.D.S.; ROCHA, F.A.; PAULA, A. Características agronômicas do feijão caupi inoculado em função de lâminas de irrigação e de níveis de nitrogênio. Revista Ceres, Viçosa, v.60, n.2, p.242-248, 2013.

TERCEIRO, E.S.; PESSÔA, U.C.M.; SOUZA, A.S.; SOARES FILHO, A.A.; PIMENTA, T.A. Aspectos fisiológicos do feijão-caupi e crescimento de tiririca (Cyperus rotundus L.) sob competição em solo compactado. Revista Verde de Agroecologia e Desenvolvimento Sustentável, Pombal, v.11, n.1, p.14-22, 2016.

VAN GENUCHTEN, M.T. A closed-form equation for predicting the conductivity of unsaturated soils. Soil Science Society of American Journal, Madison, v.44, p.892-897, 1980. 